\title{
FUNCTIONAL OUTCOME OF INTERTROCHANTERIC FRACTURE OF FEMUR TREATED WITH PROXIMAL FEMORAL NAIL FIXATION
}

\author{
Sudheer Urampath ${ }^{1}$, Rajesh Kodanga Parambil2 ${ }^{2}$ Jayaprakash Chundarathil ${ }^{3}$ \\ ${ }^{1}$ Associate Professor, Department of Orthopaedics, Amala Institute of Medical Sciences. \\ ${ }^{2}$ Resident, Department of Orthopaedics, Amala Institute of Medical Sciences. \\ 3 Professor and HOD, Department of Orthopaedics, Amala Institute of Medical Sciences.
}

\begin{abstract}
BACKGROUND

An intertrochanteric fracture occurs between the greater trochanter and the lesser trochanter, which is common in old age. If treated non-operatively, malunion with coxa vara deformity resulting in shortening of limb are commonly seen. Intertrochanteric femur fractures may be fixed with either a sliding hip screw or an intramedullary nail. Problem with sliding hip screw is collapse of the femoral neck, leading to loss of hip offset and shortening of the leg. Therefore, a new intramedullary device-proximal femoral nail (PFN) was designed which gave an advantage of minimally invasive surgery.

Objectives- To determine the functional outcome of intertrochanteric fracture treated with proximal femoral nail (PFN) by using Harris Hip Score (HHS).
\end{abstract}

\section{MATERIALS AND METHODS}

A prospective study was done among 47 patients of both gender who had undergone proximal nail fixation for intertrochanteric fracture. Patients were followed up for a period of 12 months. Functional outcome was assessed by Harris Hip Score (HHS).

\section{RESULTS}

Most of the study subjects were in 81-90 years age group (34\%). Out of 47 patients, $63.8 \%$ were female and $36.2 \%$ were male. In majority, right side (55.3\%) was affected. The mean post-operative day of mobilisation was $2.45 \pm 0.169$ days. The mean HHS score among the study subjects was assessed to be $83.83 \pm 8.36$. Almost $78 \%$ patients got good to excellent functional outcome according to Harris Hip Score.

\section{CONCLUSION}

In this study, use of proximal femoral nail in the treatment of intertrochanteric fractures produced better functional outcomes in majority of the patients.

\section{KEYWORDS}

Intertrochanteric Fracture, Proximal Femoral Nail, HHS.

HOW TO CITE THIS ARTICLE: Urampath S, Parambil RK, Chundarathil J. Functional outcome of intertrochanteric fracture of femur treated with proximal femoral nail fixation. J. Evolution Med. Dent. Sci. 2017;6(14):1143-1145, DOI: 10.14260/Jemds/2017/247

\section{BACKGROUND}

An intertrochanteric fracture occurs between the greater trochanter, where the gluteus maximus, gluteus medius and minimus muscles (Hip extensors and abductors) attach and the lesser trochanter, where the iliopsoas muscle (Hip flexor) attaches. The trochanteric fractures can be managed by conservative methods and there is usually union of the fracture. In trochanteric fractures, treated non-operatively, malunion with coxa vara deformity resulting in shortening of limb are commonly seen. ${ }^{1}$ It is also associated with complications of prolonged immobilisation like bedsores, deep vein thrombosis and respiratory infections.

Financial or Other, Competing Interest: None.

Submission 09-01-2017, Peer Review 01-02-2017,

Acceptance 08-02-2017, Published 16-02-2017.

Corresponding Author:

Dr. Sudheer Urampath,

Associate Professor,

Department of Orthopaedics,

Amala Institute of Medical Sciences,

Amalanagar-680555, Thrissur District,

Kerala.

E-mail: sudheeranortho@gmail.com

DOI: $10.14260 /$ jemds $/ 2017 / 247$
To address this, various operative procedures with different implants have been described for the treatment of intertrochanteric fractures. The primary goal of the treatment is early mobilisation, which can be achieved by internal fixation. Intertrochanteric femur fractures may be fixed with either a sliding hip screw or an intramedullary nail. A problem with sliding hip screw is collapse of the femoral neck, leading to loss of hip offset and shortening of the leg. Therefore, a new intramedullary device- proximal femoral nail was designed by AO in 1996 which gave an advantage of minimally invasive surgery. ${ }^{2}$ Proximal femoral nail fixation has advantages over sliding hip screw and plate ${ }^{3}$ like 1 . Biomechanically sound fixation. 2. Minimally invasive surgery. 3. Load bearing device. 4. Less stress riser effect at tip of nail. 5. Facilitates early mobilisation of patients especially elderly. 6. Controlled concentric collapse at fracture site leading to shortening can be minimised or prevented. 4,5 7. Less incidence of varus collapse.5,6,7 8. Shorter operative time and less soft tissue dissection. Objective of the study was to determine the functional outcome of intertrochanteric fracture treated with proximal femoral nail (PFN) by using Harris Hip Score (HHS). ${ }^{8}$ 


\section{MATERIALS AND METHODS}

A prospective study was done among 47 patients of both gender who had undergone proximal nail fixation for intertrochanteric fracture in Orthopaedic Department of Amala Institute of Medical Science, Thrissur. Patients were followed up for a period of 12 months (February 2014 to February 2015). A brief history and clinical examination were carried out for every patient. Functional outcome was assessed by Harris Hip Score (HHS). Written informed consent was taken from all patients. Data collected was entered in Microsoft excel and was analysed using Epi info software. Ethical approval was obtained. All patients were followed up at 6 weeks till fracture union was noted and then reviewed every 3 months till 1 year. During every visit, patients were assessed regarding hip and knee function, walking ability, fracture union, shortening, and deformities. Harris Hip Score was used for evaluation of functional outcome.

The Harris Hip Score interpretation (HHS). ${ }^{8}$

The hip score gives a maximum of 100 points. Pain receives 44 points, function 47 points, and deformity 9 points. The higher HHS, the less dysfunction.

\section{Total Score}

$<70$ - poor, 70-79 - fair, 80- 89 -good, 90-100 -excellent.

\section{RESULTS}

A total of 47 patients having intertrochanteric fractures treated with standard proximal femoral nail were assessed for functional outcome. The mean post-operative follow up period was 12 months.

Distribution of the Study Subjects according to Gender Out of 47 patients $30(63.8 \%)$ were female and $17(36.2 \%)$ were male.

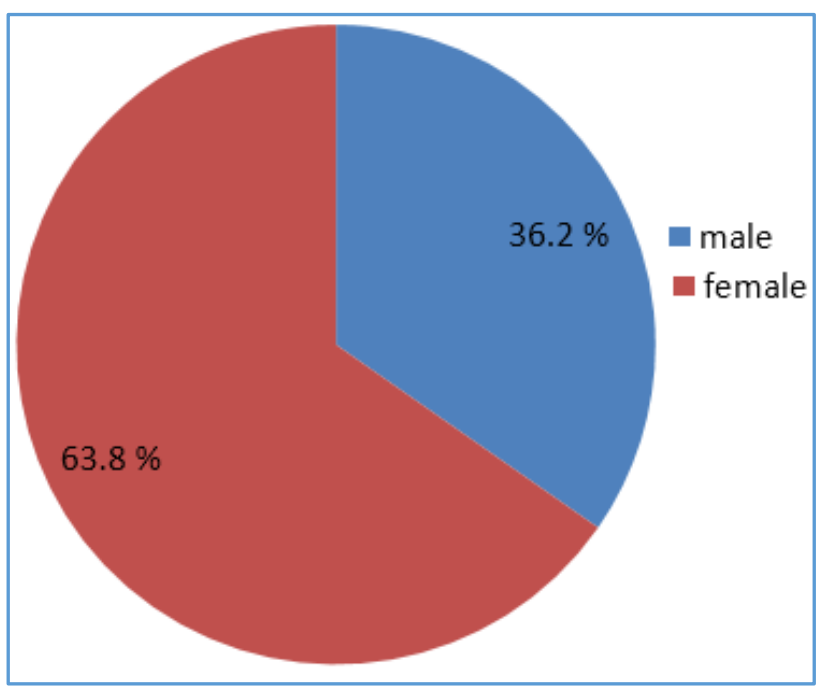

Figure 1. Gender Distribution of Study Population

\section{Distribution of the Study Subjects according to Age}

Most of the study subjects were in 81-90 years age group (34\%) which was followed by $31.9 \%$ among $71-80$ years age group. Only $2.1 \%$ were found to be among less than 50 years age group (Table no.1).

\begin{tabular}{|c|c|c|}
\hline Age & $\begin{array}{c}\text { Frequency } \\
\text { (Total No= 47) }\end{array}$ & Percent \\
\hline$\leq 50$ & 1 & 2.1 \\
\hline $51-60$ & 5 & 10.6 \\
\hline $61-70$ & 8 & 17.0 \\
\hline $71-80$ & 15 & 31.9 \\
\hline $81-90$ & 16 & 34.0 \\
\hline$\geq 91$ & 2 & 4.3 \\
\hline \multicolumn{2}{|c|}{ Table 1. Distribution of the Study Subjects } \\
According to Age Group \\
\hline
\end{tabular}

Distribution of the Study Subjects according to Side Affected

In majority of the study participants, right side (55.3\%) was affected (Table no.2).

\begin{tabular}{|c|c|c|}
\hline Side & $\begin{array}{c}\text { Frequency } \\
\text { (Total No= 47) }\end{array}$ & Percent \\
\hline Left & 21 & 44.7 \\
\hline Right & 26 & 55.3 \\
\hline \multicolumn{2}{|c|}{ Table 2. Distribution of the Study Subjects } \\
According to Side Affected \\
\hline
\end{tabular}

Functional Outcome of Intertrochanteric Fractures with Proximal Femoral Nail Fixation

The mean post-operative day of mobilisation was $2.45 \pm 0.169$ days with proximal femoral nail fixation. The mean HHS score among the study subjects was assessed to be $83.83 \pm 8.36$ after correcting intertrochanteric fractures with PFN fixation. Among $44.7 \%$ of study subjects, the functional outcome was good and among $34 \%$ the outcome was excellent. Only in $4.3 \%$ the functional outcome was poor according to HHS score.

\begin{tabular}{|c|c|c|}
\hline HHS & $\begin{array}{c}\text { Frequency } \\
\text { (Total n =47) }\end{array}$ & Percent \\
\hline Poor & 2 & 4.3 \\
\hline Fair & 8 & 17.0 \\
\hline Good & 21 & 44.7 \\
\hline Excellent & 16 & 34.0 \\
\hline \multicolumn{2}{|c|}{ Table 3. Functional Outcome using HHS Score } \\
\hline
\end{tabular}

\section{DISCUSSION}

In this study, female population (63.8\%) was more affected compared to males owing to the fact that they are more osteoporotic. A study conducted by Melton J. L., Ilistrup DM, Riggs BL et al (1982) titled 'fifty years trend in Hip fracture incidence' and reported a female to male ratio of $1.8: 1$. $^{7}$ According to a study by Scott in 1951 \& Robey in 1956, the male to female ratio was 1.85 and 1.15 respectively. Cleveland et $\mathrm{al}^{9}$ in their study had $87.7 \%$ of female patients. H. B. Boyd and L. L. Griffin ${ }^{10}$ in their study of 300 cases, 226 (75.8\%) of the patients were female and 74 (24.2\%) were male. Most of the patients in this study were elderly people. The mean age of patients in this study was 75.21 years. This indicates the fact that patients from these age groups are involved in low energy trauma like domestic fall (Fall at home). ${ }^{11}$ According to Gallagher et al (1980), there is an eight fold increase in trochanteric fractures in men over 80 years and women over 50 years of age.12 Nuber S Schonweiss et al (2005) observed the mean age of 81.5 years in their study. 
Huang et al (2010) observed in their study, the mean age of 75 years. The proximal femoral nail fixation has small incision, less blood loss, minimum soft tissue dissection, less duration of surgery and low morbidity. This technique facilitated early mobilisation of the patient. Most of the patients in this study started mobilising on the second postoperative day. This was followed by bed-to-chair transfer, non-weight bearing mobilisation with the help of walkers. Almost 78\% patients got good to excellent functional outcome according to Harris Hip Score. Only $4 \%$ of the patients had poor functional outcome. The Harris Hip Score shows that proximal femoral nail fixation has advantages in functional outcome.

\section{CONCLUSION}

In this study, use of proximal femoral nail in the treatment of intertrochanteric fractures produced better functional outcome in majority of study subjects. So this treatment can be recommended for good results in the management of intertrochanteric fractures.

\section{Acknowledgment}

I express my heartfelt gratitude to my all colleagues in the department for their painstaking efforts in completion of this study in a better way.

\section{REFERENCES}

[1] Falch JA, Liebekk A, Slungaard U. Epidemiology of hip fractures in Norway. Acta Orthop Scand 1986;56:12-16.

[2] Simmermacher RK, Bosch AM, Van der Werken C. The AO/ASIF-Proximal Femoral Nail (PFN): a new device for the treatment of unstable proximal femoral fractures. Injury 1999;30(5):327-32.

[3] Bucholz RW, Heckman JD, Koval KJ, et al. Rockwood and Green's fractures in adults. $6^{\text {th }}$ edn. Philadelphia: Lippincott Williams \& Wilkins 2005.
[4] Sudhir BS. Management of trochanteric fractures. Department of Orthopaedics, Indira Gandhi Medical College, Nagpur. Indian Journal of Orthopaedics 2006;40(4):210-18.

[5] Gadegone WM, Salphale YS. Short proximal femoral nail fixation for trochanteric fractures. Department of Orthopaedics and Traumatology, Chandrapur multispeciality hospital, Chandrapur, India. Journal of Orthopaedic Surgery 2010;18(1):39-44.

[6] Windolf J, Hollander DA, Hakimi M, et al. Pitfalls and complications in the use of the proximal femoral nail. Journal Langenbeck's Archives of Surgery 2005;390(1): 59-65.

[7] Pynsent PB, Fairbank JCT, Carr A. Textbook on outcome measures in orthopaedics. The Harris hip score outcome measures in clinical orthopaedics. Oxford, Boston: Butterworth-Heinemann 1993;10:223-6.

[8] Berman AT, Metzger PC, Bosacco SJ, et al. Treatment of the subtrochanteric fracture with the compression hip nail: a review of 138 consecutive cases. Orthop Trans 1979;3:225-56.

[9] Cleveland M. A ten year analysis of intertrochanteric fractures. JBJS 1983;63B:218.

[10] Griffin JB. The calcar femorale redefined. Clin Orthop Relat Res 1982;164:211-4.

[11] Dean GL, David S, Jason HN. Osteoporotic pertrochanteric fracture: management and current controversies. J Bone Joint Surg Am 2004;72 B:737-52.

[12] Gallagher JC, Melton LJ, Riggs BL, et al. Epidemiology of fractures of the proximal femur in Rochester, Minnesota. Clinical Orthop Relat Res 1980;150:163-71. 